Original Research - Quantitative

\title{
Factors affecting intention to breastfeed of a group of Brazilian childbearing women
}

\author{
S.A.S. Moimaz ${ }^{\text {a }}$ N.B. Rocha ${ }^{\text {b** }}$, C.A.S. Garbin ${ }^{a}$, T.A. Rovida ${ }^{a}$, N.A. Saliba ${ }^{a}$ \\ a Preventive and Social Dentistry Department, School of Dentistry, São Paulo State University (UNESP), Araçatuba, Brazil \\ ${ }^{\mathrm{b}}$ Public Health Graduate Program, School of Dentistry, São Paulo State University (UNESP), Araçatuba, Brazil
}

\section{A R T I C L E I N F O}

\section{Article history:}

Received 28 January 2016

Received in revised form 9 September 2016

Accepted 14 October 2016

\section{Keywords:}

Breastfeeding

Breastfeeding difficulties

Breastfeeding initiation

Brazil

Pregnancy

\begin{abstract}
A B S T R A C T
Background: Knowing the intention of mothers is important to plan actions to improve exclusive breastfeeding rates.

Aim: The objective of this retrospective study was to verify the intention to breastfeed and the intended breastfeeding duration of a group of women participating in a public prenatal dental care program in the city of Araçatuba, Brazil.

Methods: The records of 933 childbearing women were analyzed and their intention to breastfeed and intended breastfeeding duration were associated to women's age, ethnicity, marital status, education, employment, number of gestations, previous breastfeeding experience, previous breastfeeding guidance, presence of complications during pregnancy, and systemic diseases. Data were inserted into Epi Info 2000 and analyzed with Biostat, at a 5\% level of significance, and confidence interval of 95\%.

Findings: Participants mean age was $26.1 \pm 5.9$ years. The majority of women $(96.5 \%)$ declared their intention to breastfeed their babies. The main variables to affect the intention to breastfeed were the number of gestations $(p=0.001)$, previous breastfeeding experience $(p=0.03)$, and previous breastfeeding guidance $(p=0.01)$. Intended breastfeeding duration was significantly affected by women's age $(p=0.04)$, employment $(0.02)$, the number of gestations $(p=0.001)$, and previous breastfeeding experience $(\mathrm{p}=0.04)$.

Conclusions: Previous positive breastfeeding experience and guidance during prenatal examinations positively affected women's intention to breastfeed; while older, unemployed women in their second or more gestation and previous breastfeeding experience intended to breastfeed their children for longer periods of time.
\end{abstract}

(c) 2016 Australian College of Midwives. Published by Elsevier Ltd. All rights reserved.
Statement of significance

\section{Problem or issue}

Breastfeeding brings unquestionable nutritional, immunological, psychological and economic benefits both to mothers and babies, but its practice in Brazil tends to be discontinued early after the baby is born.

\footnotetext{
* Corresponding author at: UNESP-Universidade Estadual Paulista, Faculdade de Odontologia, Rua José Bonifácio, 1193-Vila Mendonça, 16015-050 Araçatuba, São Paulo, Brazil.

E-mail addresses: sasaliba@foa.unesp.br (S.A.S. Moimaz), najaraunesp@hotmail.com, najara.rocha@gmail.com (N.B. Rocha), cgarbin@foa.unesp.br (C.A.S. Garbin), tasalibarovida@foa.unesp.br (T.A. Rovida), nemre@foa.unesp.br (N.A. Saliba).
}

\section{What is already known}

The intention to breastfeed is indicated as one of the strongest predictors of the initiation and duration of breastfeeding.

\section{What this paper adds}

The evidence emerging from this study suggests that strategies should be developed and supported by all state health and dental services during the prenatal period to incentive breastfeeding. Particular attention should be given to primigravid women, who may be more reluctant to breastfeed their babies. 


\section{Introduction}

Breast milk provides babies the best possible nutrition and protection against infection during the first months of life and has a fundamental role in their development. ${ }^{1-3}$ The act of breastfeeding (BF) brings unquestionable benefits to both the general and oral health of the baby throughout life. ${ }^{1-6}$ According to the latest UNICEF update (2015), the prevalence of exclusive breastfeeding in Brazil up to six months of age is $39 \%{ }^{7}$ Data from the Brazilian Ministry of Health indicate that mean BF duration increased from 296 to 342 days, while exclusive BF raised from 23.4 to 54.1 days in the period between 1999-2008.8,9 Despite the improvements observed in the last few years, BF rates still fall short from those recommended by national and international organizations, that is, exclusive breastfeeding until the baby is at least six months old, to be followed in complemented form up to two years or more. ${ }^{1-3}$ Although considered natural and instinctive, BF can be affected by numerous biological, social, historical and cultural factors. ${ }^{10-12}$ According to Scavenius et al. ${ }^{12}$ social constraints in relation to $\mathrm{BF}$ may develop, leading to decreased suckling and eventually to the cessation of BF.

The intention to breastfeed expressed by mothers during pregnancy is considered one of the strongest predictors of the initiation and duration of breastfeeding. ${ }^{13-19}$ The stronger the intention to breastfeed during the prenatal period, the more likely the mother will exclusively breastfeed after the baby is born. ${ }^{16}$ Previous studies showed that the intention reported by childbearing women in Brazil to breastfeed their babies is extremely high. ${ }^{18,19}$ In a study conducted by Issler et al. ${ }^{18} 98.5 \%$ of women studied reported the intention to breastfeed, while in a more recent study by Machado et al. ${ }^{19}$ this prevalence was even higher (100\%).

In a country of continental size such as Brazil, with large social, ethnic and cultural differences, the challenges for the development of health in the population in general are enormous. Studies have shown that many women are reluctant to seek dental care during the pregnancy period, except in situations of emergency. The reasons for this behavior are rooted in cultural beliefs that dentistry is merely curative, as well as the fears and anxieties related to dental treatment. ${ }^{20,21}$ Thus, public programs dedicated to change this scenario and highlight the importance of oral care for both mothers and their babies can have a positive impact on their health. ${ }^{22}$

In line with this perception, a public dental school in the city of Araçatuba (Brazil) has established a dental care program specifically designed for childbearing women. ${ }^{22}$ Local childbearing women who are cared for by the public health system are invited to participate in the program, where in addition to receiving oral care, they also receive information on the importance of breastfeeding on the oral health of their children. Women interested in participating in the program are closely followed by dental students and college professors, and detailed information are collected. The investigation of this particular group of women has the potential to bring to light some important evidence about the intention to breastfeed, which, in turn, could help in action planning to improve BF rates in the general population.

Thus, the objective of this study was to verify the intention to breastfeed and the intended BF duration of a group of women participating in a public prenatal dental care program in relation to the different variables that may affect this decision.

\section{Participants, ethics and methods}

This was a retrospective and descriptive study, in which data obtained from the records of participants in the Dental Care Program for Childbearing Women were analyzed. This study was conducted in accordance with The Code of Ethics of the World Medical Association (Declaration of Helsinki) for experiments involving humans, and was approved by the Standing Committee on Ethics in Human Research of Araçatuba Dental School (FOA), São Paulo State University (UNESP), Brazil. All the patients signed an informed consent for the use of the information collected during their participation in the program in future research.

\subsection{Dental care program}

The Dental Care Program for Childbearing Women was established in 1999 in the city of Araçatuba, Brazil under the responsibility of dental students and college professors of FOA-UNESP, Brazil. ${ }^{22}$ This program is intended to promote the dental health of local childbearing women cared for by the national public health system. These are in general young women, who come from the economic lower end of society and join the program in the second quarter of their gestational period. Dental students visit local public health centers and invite childbearing women to participate in the program. In addition to the main objective (to ensure adequate dental health of mothers before babies are born), emphasis is also placed on the importance of BF on the general and dental health of their future babies.

Before starting dental treatment, childbearing women attend an educational workshop on the importance of oral health for mothers and their babies, prevention of oral diseases, diet, and self-care. Groups discussions are conducted with the use of audiovisual resources and the active participation of mothers. Although the program is free and open to anyone interested, only approximately $30 \%$ of the women invited attend the initial workshop.

In the first clinical consultation, intra and extraoral examinations are performed, instructions on oral hygiene and dental plaque control are provided, and supervised brushing is conducted. During this first visit, mothers are also individually interviewed and data concerning their socio-demographic status, general health, diet, intention to breastfeed, and previous BF experience are collected.

In subsequent consultations, preventive and/or restorative treatment is conducted by college students under the guidance of professors. In the last visit, mothers participate in a second educational workshop, similar to the first, in which any doubts they may still have on the oral health of their babies are clarified. Moreover, mothers also receive specific education and incentive on $\mathrm{BF}$ practice, exclusive BF, and BF duration. The clinical records of the childbearing women are then scanned and entered into an electronic database.

\subsection{Study design}

The medical records of all participants $(n=1020)$ since the start of the program in March 1999 till August 2014 were analyzed. Childbearing women who did not complete the treatment were excluded from the study. The following data were collected from the records:

- Age ( $\leq 18$ years, 19-30 years, >30 years);

- Ethnicity (white, or non-white);

- Marital status (with, or without a steady partner);

- Education (primary education, or secondary education and higher);

- Employment (yes or no);

- Number of gestations (primigravid, or two or more);

- Previous BF experience (yes or no);

- Previous BF guidance (yes or no).

- Systemic diseases (yes or no); and 
- Complications during the pregnancy (yes or no);

These variables were correlated to the childbearing women's:

- Intention to breastfeed (yes or no); and

- Intended BF duration ( $\leq 4$ months, 5-6 months, >7 months)whenever childbearing women reported not knowing how long they intended to breastfeed, this variable was excluded from the analysis.

The information collected from medical records were entered in Epi Info Program 2000,23 and subsequently checked by two researchers independently. Data were analyzed with Biostat, version $5.3 .^{24}$

\subsection{Statistical analysis}

Statistical analysis included descriptive and inferential analysis with a significance level of $\mathrm{p} \leq 0.05$ and confidence interval (CI) of $95 \%$. The results of the associations observed in the bivariate analysis of the variables related to the intention to breastfeed presenting value $\mathrm{p} \leq 0.20$ were included in the multiple logistic regression analysis, and presented using frequencies and Odd Ratio (OR) with $95 \% \mathrm{CI}$.

\section{Results}

Of the 1020 existing records, 933 were selected for analysis in the study. The records of 87 women demonstrated that they did not complete their treatment, and were excluded from the analysis. Fig. 1 shows the numerical distribution of childbearing women in relation to their intention to breastfeed over the 15-year period of the program (1999-2014). Despite the variation in the number of participating women, the intention to breastfeed was relatively uniform during the period.

Social-demographic and other information retrieved from the records are presented in Table 1 . Most of the participating women (65.5\%) were between 19 and 30 years (mean age $26.1 \pm 5.9$ years), white (60.8\%), unemployed (57.2\%), primigravid (54\%), had secondary education or higher (51.4\%), lived with their partners (75.4\%), presented no complications during pregnancy (76.5\%), and no systemic conditions (89.7\%).

Overall, the intention to breastfeed expressed by participants in the program was very high, with $96.5 \%$ of the childbearing women saying they intended to breastfeed their babies, while just 3.5\% explicitly said otherwise. Bivariate associations between the variables studied and the intention to breastfeed are also presented in Table 1. Primigravid mothers demonstrated a significantly lower

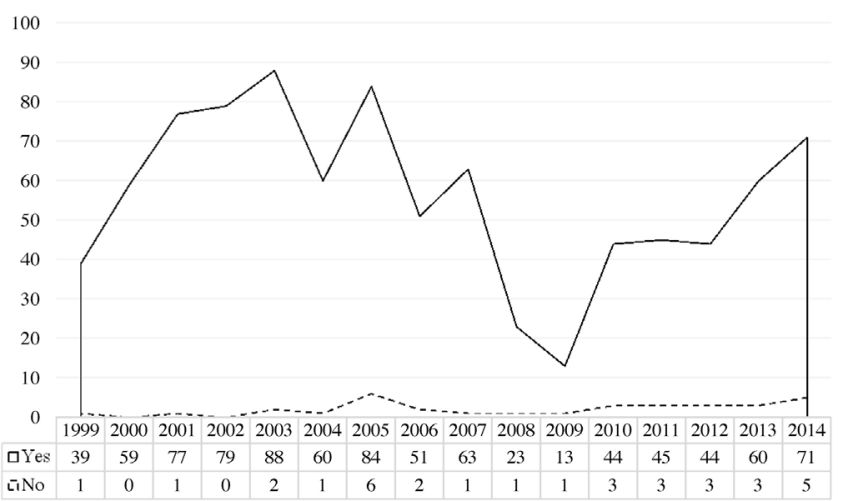

Fig. 1. Distribution of participants since the start of the Dental Care Program for Pregnant Women over the years in relation to their intention to breastfeed.
Table 1

Bivariate analysis of the intention to breastfeed of pregnant women in relation to the studied variables.

\begin{tabular}{|c|c|c|c|c|}
\hline \multirow[t]{2}{*}{ Variables } & \multirow[t]{2}{*}{ Total N (\%) } & \multicolumn{2}{|c|}{ Intention to breastfeed } & \multirow[t]{2}{*}{$\mathrm{p}$} \\
\hline & & $\begin{array}{l}\text { Yes } \\
\mathrm{N}(\%)\end{array}$ & $\begin{array}{l}\text { No } \\
\mathrm{N}(\%)\end{array}$ & \\
\hline Age (Years) & $927(100 \%)$ & $\begin{array}{l}894 \\
(96,4 \%)\end{array}$ & $33(3.6 \%)$ & 0.87 \\
\hline$\leq 18$ & 97 (10.5\%) & $94(97 \%)$ & $3(3 \%)$ & \\
\hline $19-30$ & $\begin{array}{l}607 \\
(65,5 \%)\end{array}$ & $584(96.2 \%)$ & $23(3.8 \%)$ & \\
\hline$>30$ & $223(24 \%)$ & $216(96.8 \%)$ & $7(3.2 \%)$ & \\
\hline Ethnicity & $853(100 \%)$ & $\begin{array}{l}823 \\
(96.5 \%)\end{array}$ & $30(3.5 \%)$ & 0.63 \\
\hline White & $519(60.8 \%)$ & $499(96.1 \%)$ & $20(3.9 \%)$ & \\
\hline Non-white & $\begin{array}{l}334 \\
(39.2 \%)\end{array}$ & $324(97 \%)$ & $10(3 \%)$ & \\
\hline Marital status & $929(100 \%)$ & $\begin{array}{l}896 \\
(96.4 \%)\end{array}$ & $33(3.6 \%)$ & 0.32 \\
\hline With partner & $701(75.4 \%)$ & 679 (96.9\%) & $22(3.1 \%)$ & \\
\hline Without partner & $\begin{array}{l}228 \\
(24.6 \%)\end{array}$ & $217(95.2 \%)$ & $11(4.8 \%)$ & \\
\hline Education & $927(100 \%)$ & $\begin{array}{l}894 \\
(96.4 \%)\end{array}$ & $33(3.6 \%)$ & 0.87 \\
\hline Primary & $451(48.6 \%)$ & $434(96.2 \%)$ & $17(3.8 \%)$ & \\
\hline Secondary or higher & $476(51.4 \%)$ & $460(96.6 \%)$ & $16(3.4 \%$ & \\
\hline Employment & $880(100 \%)$ & $\begin{array}{l}848 \\
(94.4 \%)\end{array}$ & $32(3.6 \%)$ & 0.77 \\
\hline Yes & $377(42.8 \%)$ & $362(96 \%)$ & $15(4 \%)$ & \\
\hline No & $503(57.2 \%)$ & $486(96.6 \%)$ & $17(3.8 \%)$ & \\
\hline Number of gestations & $912(100 \%)$ & $\begin{array}{l}879 \\
(96.4 \%)\end{array}$ & $33(3.6 \%)$ & $0.001^{\mathrm{a}}$ \\
\hline Primigravid & $492(54 \%)$ & $482(98 \%)$ & $10(2 \%)$ & \\
\hline Two or more & $420(46 \%)$ & 397 (94.5\%) & $23(5.5 \%)$ & \\
\hline $\begin{array}{l}\text { Complications during } \\
\text { pregnancy }\end{array}$ & $920(100 \%)$ & $\begin{array}{l}888 \\
(95.6 \%)\end{array}$ & $32(3.4 \%)$ & 0.66 \\
\hline Yes & $216(23.5 \%)$ & 210 (97.2\%) & $6(2.8 \%)$ & \\
\hline No & $704(76.5 \%)$ & $678(96.3 \%)$ & $26(3.7 \%)$ & \\
\hline Previous BF experience & $192(100 \%)$ & $185(96.4 \%)$ & $7(3.6 \%)$ & $0.10^{\mathrm{a}}$ \\
\hline Yes & $164(85.4 \%)$ & $160(97.6 \%)$ & $4(2.4 \%)$ & \\
\hline No & $28(14.6 \%)$ & $25(89.3 \%)$ & $3(10.7 \%)$ & \\
\hline Previous BF guidance & $928(100 \%)$ & $\begin{array}{l}895 \\
(96.4 \%)\end{array}$ & $33(3.6 \%)$ & $0.02^{\mathrm{a}}$ \\
\hline Yes & $\begin{array}{l}698 \\
(75.2 \%)\end{array}$ & $679(97.3 \%)$ & $19(2.7 \%)$ & \\
\hline No & $\begin{array}{l}230 \\
(24.8 \%)\end{array}$ & $216(93.9 \%)$ & $14(6.1 \%)$ & \\
\hline Systemic diseases & $902(100 \%)$ & $870(96.4 \%)$ & $32(3.6 \%)$ & 0.62 \\
\hline Yes & $93(10.3 \%)$ & $91(97.8 \%)$ & $2(2.2 \%)$ & \\
\hline No & $\begin{array}{l}809 \\
(89.7 \%)\end{array}$ & $779(96.3 \%)$ & $30(3.7 \%)$ & \\
\hline
\end{tabular}

a Predictor variables considered for the logistic regression analyzes. BF: breastfeeding.

intention to breastfeed their babies than women who were pregnant for the second time or more $(p=0.001)$. Childbearing women who had received previous BF guidance demonstrated a significantly higher intention to breastfeed than those who had not $(\mathrm{p}=0.02)$. Although not statistically significant in the bivariate analysis, previous $\mathrm{BF}$ experience also could have an impact on the intention to breastfeed $(\mathrm{p}=0.10)$.

Variables in the bivariate analysis showing $\mathrm{p} \leq 0.20$ were also analyzed with multiple logistic regression (Table 2 ). The variable number of gestations was no longer significant $(p=0.61)$, while the variable previous BF experience demonstrated statistical 
Table 2

Multiple logistic regression analysis of the associations the intetion to breastfeed and the variables with $\mathrm{p} \leq 0.20$ in the bivaried analysis.

\begin{tabular}{llrlll}
\hline Variables & \multicolumn{7}{l}{ Intention to breastfeed } \\
\cline { 2 - 7 } & $\mathrm{p}$ & Coef. & Standadard error & OR & IC (95\%) \\
\hline Number of gestations & 0.61 & -0.42 & 0.84 & 0.65 & $0.02-0.68$ \\
Previous BF experience & 0.03 & 1.84 & 0.85 & 6.31 & $1.17-6.93$ \\
Previous BF guidance & 0.01 & -2.17 & 0.90 & 0.11 & $0.02-0.68$ \\
\hline
\end{tabular}

BF: breastfeeding.

significance $(p=0.03)$, and the variable previous BF guidance was confirmed $(\mathrm{p}=0.01)$.

In general, $2.6 \%$ of the childbearing women declared to intend to breastfeed their babies up to 4 months, $34 \%$ up to 6 months, $29.9 \%$ for more than 6 months, while 33.5\% said they did not know how long they would breastfeed their babies. The associations between the variables studied and the intended BF duration are presented in Table 3. Intended $\mathrm{BF}$ duration was significantly affected by women's age $(p=0.04)$, employment $(0.02)$, the number of gestations $(\mathrm{p}=0.001)$, and previous $\mathrm{BF}$ experience $(p=0.04)$. Thus older, unemployed women in their second or more gestation and previous $\mathrm{BF}$ experience intended to breastfeed their children for longer periods of time.

\section{Discussion}

The objective of this retrospective and descriptive study was to analyze the intention to breastfeed and the intended BF duration of a group of women who participated in a dental care program established by a State Dental School in Brazil. The strength of this study lies on the number of women investigated, the period of the investigation, and especially on the fact that this group of women demonstrated interest for their oral health during their gestation. The results found demonstrated that almost the totality of the women (96.5\%) intended to breastfeed their children and, among those who declared their intention, the majority said they wanted to breastfeed for 5 months or more.

Several previous studies have shown that breastfeeding intention expressed during pregnancy is a strong predictor for the onset and duration of breastfeeding. ${ }^{13,15}$ According to the planned behavior theory, an intended act is recognized as a determinant factor of immediate behavior. ${ }^{25}$ The intention is influenced by three constructs: attitudes (based on perceptions of the advantages and disadvantages of performing a behavior), subjective norms (perceptions of approval of others to perform the behavior), and perceived behavioral control (perceptions on the level of control that the person believes to have to perform the behavior). ${ }^{25}$ The very high intention (96.5\%) to breastfeed found in

Table 3

Bivariate analysis of the intended breastfeeding duration of pregnant women in relation to the studied variables.

\begin{tabular}{|c|c|c|c|c|c|}
\hline \multirow[t]{2}{*}{ Variables } & \multirow[t]{2}{*}{ Total N (\%) } & \multicolumn{3}{|c|}{ Intention to breastfeed } & \multirow[t]{2}{*}{$\mathrm{p}$} \\
\hline & & $\begin{array}{l}\leq 4 \text { months } \\
\mathrm{N}(\%)\end{array}$ & $\begin{array}{l}\text { 5-6 months } \\
\mathrm{N}(\%)\end{array}$ & $\begin{array}{l}>6 \text { months } \\
\mathrm{N}(\%)\end{array}$ & \\
\hline Age (Years) & $566(100 \%)$ & $24(4.2 \%)$ & $273(48.2 \%)$ & $269(47.6 \%)$ & 0.04 \\
\hline$\leq 18$ & $35(6.2 \%)$ & $4(11.4 \%)$ & $10(28.6 \%)$ & $21(60 \%)$ & \\
\hline $19-30$ & $388(68.5 \%)$ & $12(4 \%)$ & $202(52.1 \%)$ & $174(44.9 \%)$ & \\
\hline$>30$ & $143(25.3 \%)$ & $8(5.6 \%)$ & $61(42.6 \%)$ & $74(51.8 \%)$ & \\
\hline Skin color & $551(100 \%)$ & $21(3.8 \%)$ & $284(51.5 \%)$ & $246(44.7 \%)$ & 0.26 \\
\hline White & $325(59 \%)$ & $9(2.8 \%)$ & 166 (51.1\%)\%) & $150(46.1 \%)$ & \\
\hline Non-white & $226(41 \%)$ & $12(5.3 \%)$ & $118(52.2 \%)$ & $96(42.5 \%)$ & \\
\hline Marital status & $597(100 \%)$ & $24(4 \%)$ & 305 (51.1\%) & 268 (44.9\%) & 0.47 \\
\hline With partner & $447(74.8 \%)$ & $18(4 \%)$ & $222(49.7 \%)$ & 207 (46.3\%) & \\
\hline Without partner & $150(25.1 \%)$ & $6(4 \%)$ & $83(55.3 \%)$ & $61(40.7 \%)$ & \\
\hline Education & $595(100 \%)$ & $24(4 \%)$ & 305 (51.3\%) & $266(44.7 \%)$ & 0.17 \\
\hline Primary & $276(46.4 \%)$ & $9(3.3 \%)$ & $151(54.7 \%)$ & $116(42 \%)$ & \\
\hline Secondary or higher & $319(53.6 \%)$ & $15(4.7 \%)$ & $154(48.3 \%)$ & $150(47 \%)$ & \\
\hline Employment & $630(100 \%)$ & $24(3.8 \%)$ & 351 (55.7\%) & 255 (40.5\%) & 0.02 \\
\hline Yes & $292(46.3 \%)$ & $7(2.4 \%)$ & $152(52 \%)$ & $133(45.6 \%)$ & \\
\hline No & $338(53.7 \%)$ & $17(5 \%)$ & $199(58.9 \%)$ & $122(36.1 \%)$ & \\
\hline Number of gestations & $595(100 \%)$ & $31(5.2 \%)$ & $298(50.1 \%)$ & 266 (44.7\%) & 0.001 \\
\hline Primigravid & $278(46.7 \%)$ & $11(3.9 \%)$ & $159(57,2 \%)$ & $108(38.9 \%)$ & \\
\hline Two or more & $317(53.3 \%)$ & $20(6.3 \%)$ & $139(43.9 \%)$ & $158(49.8 \%)$ & \\
\hline Complications during pregnancy & $592(100 \%)$ & $24(4 \%)$ & $305(51.6 \%)$ & $263(44.4 \%)$ & 0.08 \\
\hline Yes & $451(76.2 \%)$ & $14(3.1 \%)$ & $238(52.8 \%)$ & $199(44.1 \%)$ & \\
\hline No & $141(23.8 \%)$ & $10(7.1 \%)$ & $67(47.5 \%)$ & $64(45.4 \%)$ & \\
\hline Previous BF experience & $141(100 \%)$ & $12(8.5 \%)$ & 55 (39.\%) & $74(52.5 \%)$ & 0.04 \\
\hline Yes & $121(85.8 \%)$ & $11(9.1 \%)$ & $42(34.7 \%)$ & $68(56.2 \%)$ & \\
\hline No & $20(14.2 \%)$ & $1(5 \%)$ & $13(65 \%)$ & $6(30 \%)$ & \\
\hline BF guidance & $596(100 \%)$ & $24(4 \%)$ & $305(51.2 \%)$ & $267(44.8 \%)$ & 0.63 \\
\hline Yes & $151(25.3 \%)$ & $8(5.3 \%)$ & 75 (49.7\%) & $68(45 \%)$ & \\
\hline No & $445(74.7 \%)$ & $16(3.6 \%)$ & $230(51.7 \%)$ & $199(44.7 \%)$ & \\
\hline Systemic diseases & $576(100 \%)$ & $23(4 \%)$ & 294 (51\%) & 259 (45\%) & 0.25 \\
\hline Yes & 57 (9.9\%) & 0 & 29 (50.9\%) & 28 (49.1\%) & \\
\hline No & $519(90.1 \%)$ & $23(4.4 \%)$ & $265(51 \%)$ & $231(44.6 \%)$ & \\
\hline
\end{tabular}

BF: breastfeeding. 
this study may be explained by the fact that in Brazil, governmental campaigns to incentive exclusive breastfeeding have been very ostensive in past years, and women in general believe that $\mathrm{BF}$ is best for their infants. ${ }^{26}$ Thus, our results are similar to previous studies conducted in Brazil by Issler et al. ${ }^{18}$ and Machado et al. ${ }^{19}$ who also reported very high intention to breastfeed (98.5\% and $100 \%$, respectively) in the general population.

When the data over the 15-year period of the program (Fig. 1) is analyzed, the number of women who expressly indicated their intention not to breastfeed their babies seems to be on the rise. Although further studies would be required to better ascertain this trend, this data could indicate that present BF policies may be failing to achieve the desired targets. Although the number of women involved in this study that explicitly declared their intention not to breastfeed is small (3.5\%), they represent a group who require special attention. ${ }^{16}$ General and oral health care programs during the prenatal period should target these women as soon as this negative intention is expressed, in order to identify the reasons behind this choice and establish strategies for changes.

The number of gestations and previous breastfeeding experience both affected the intention to breastfeed and the intended BF duration. Together with the significant effect of previous $B F$ guidance on the intention to breastfeed, these results demonstrate the importance of health programs and professionals during the prenatal period in order to increase the positive intention to breastfeed. ${ }^{14}$ Prenatal education has already been shown to have a significant impact on the intention of breastfeed. ${ }^{4,16,22}$ The results found in this study clearly demonstrate that when the women did not receive $\mathrm{BF}$ guidance during the prenatal period, it had a negative impact on their intention to breastfeed (Table 1 ). The fact that $25 \%$ of the participating women declared to have received no counseling during their prenatal examinations is concerning. Efforts should be focused on BF education from the the first visit to the doctor in order to clarify the biological as well as the social aspects of BF. From the results found in this study it is possible to infer that prenatal education would create a cascade effect. Once women have a positive experience breastfeeding their babies for the first time they would feel more confident to continue to do so in future gestations.

An interesting aspect of this study concerns the fact that most of the participating women (54\%) were in their first pregnancy. This high number of primigravid women may be explained by the fact that participation in the program is voluntary and women in this group are probably more concerned, and sometimes more insecure, about themselves and their babies than women who have had the experience of other pregnancies. ${ }^{27}$ As observed in this study, women with more than one child declared a significantly higher intention to breastfeed their children than primigravid women; a result that has also been observed previously in a another study. ${ }^{14}$ It seems that more specific strategies should be developed to deal with primigravid women during the prenatal period to incentive mothers to appreciate the nature of the BF process. $^{12}$

Among those women who declared the intended BF duration, the vast majority (over 90\%) said they wanted to breastfeed their children for 5 months or more. A previous study conducted in Brazil showed that women intended to exclusively breastfeed their babies for an average of 5.5 months. ${ }^{19}$ However, it is important to remember that the actual BF behavior cannot be explained simply in terms of the intentions of the mothers without taking into account the social context. ${ }^{12}$ A study conducted by Marques et al. ${ }^{28}$ demonstrated that $80 \%$ of the mothers complemented BF with bottle milk from the second week after birth. A systematic review conducted in Brazil on the factors that affect breastfeeding in the first 6 months demonstrated that the age of mothers was an important variable. It showed that teenage women, and women over 35 years tend to interrupt breastfeeding earlier than mothers in intermediate ages. ${ }^{29}$ Employment has also been associated with a shorter breastfeeding time due to the difficulties met after women return to work. ${ }^{30}$ These mothers need to be better instructed on how to breastfeed their babies when they are back to work. Employment does not need to be an impairment to BF. The Brazilian law reserves two periods of 30 min daily for mothers to collect breast milk to be offered to their children during their absence. $^{31}$

Another relevant finding in this study was the fact that a considerable number of women who declared their intention to breastfeed (33.6\%) did not have a concrete position concerning how long they would like to breastfeed their children. In a previous study, Issler et al. ${ }^{18}$ found that less than half of the childbearing women interviewed had an objective intention about BF duration. In the present study, the high number of undecided women may be attributed to the the fact that most mothers were primigravid with no previous experience, probably associated to the lack of adequate $\mathrm{BF}$ information on the practice of breastfeeding during prenatal examinations. This indicates that more emphasis should be placed on $\mathrm{BF}$ education by the different dental and healthcare professionals along the prenatal period, so that childbearing women can more clearly understand the effect of BF on their babies health and are incentived to continue $\mathrm{BF}$ for as long as possible.

Despite the inherent limitations of retrospective studies such as this, it was possible to identify some trends and vulnerabilities of a system which is intended to provide women and their children adequate health care. One important question not addressed by this study was about whether women intended to exclusively breastfeed their babies and how long they intended to do that for. Unfortunately, these data was not available in the records analyzed. This information would be important not only to improve the $\mathrm{BF}$ guidance provided by the dental care program, but also in the establishment of state policies on BF. Suggestions have been made in order to have these data available in the records for future analysis.

The results of this study demonstrated that there is a clear necessity to better prepare childbearing women to breastfeed their infants. During prenatal examinations, vulnerable and misinformed women should be more promptly identified and their problems tackled in order to clarify the benefits of the BF process for both the mother and the child. ${ }^{13,17-19}$ Moreover, mothers should be followed up after the birth of their children by health professionals in order to ensure that exclusive breastfeeding is maintained for at least the first 6 months of life. ${ }^{13}$ A recent experiment in public health intervention in Brazil that involved home visits over a period of several months substantially increased both the duration and rates of exclusive breastfeeding. ${ }^{32}$ Taking into consideration that Brazil is still a poor country, the protection offered by breast milk is a fundamental health issue for the future of children. It is hoped that the information provided here can give support to the planning of policies for the incentive of exclusive breastfeeding during both general and dental health programs.

\section{Conclusion}

Based on the results of this study, it may be concluded that mothers who had previous positive BF experience and those who received $\mathrm{BF}$ guidance during the prenatal period were more likely to declare their intention to breastfeed. Whereas mothers who were older, unemployed, with more than one child and with previous BF experience were more likely to breastfeed their children for longer periods of time. 


\section{Acknowledgements}

The authors wish to thank all the women who participated in this research and their families. We would also like to thank the Brazilian Federal Agency for Support and Evaluation of Graduate Education (CAPES) and the Agency of the São Paulo Research Foundation (FAPESP) for providing funding for this study.

\section{References}

1. World Health Organization. Indicators for assessing breastfeeding practices. Geneva: WHO; 2007 Available from: www.who.int/nutrition/publications iycf_indicators_for_peer_review.pdf.

2. The United Nations Fund for Children. Tracking Progression Child and Maternal Malnutrition: A Survival and Development Priority. Available from: www.unicef. pt/docs/Progress_on_Child_and_Maternal_Nutrition_EN_110309.pdf.

3. Brazil Ministry of Health, Department of Health Care, Department of Primary Care. Ten steps to healthy eating: food guide for children under two years: a guide for health professionals in primary care. 2nd ed. Brasilia: Ministry of Health; 2010.

4. Kramer MS, Kakuma R. Optimal duration of exclusive breastfeeding. Cochrane Database Syst Rev 2012;D003517.

5. Academy of Breastfeeding Medicine Protocol Committee. Clinical protocol number \#19: breastfeeding promotion in the prenatal setting. Breastfeed Med 2009;4(1):43-5.

6. Moimaz SAS, Saliba O, Lolli LF, Garbin CAS, Garbin AJI, Saliba NA. A longitudinal study of the association between breastfeeding and harmful oral habits. Pediatr Dent 2012;34(2):117-21.

7. The United Nations Fund for Children. The World's Children 2015 Country Statistical tables [Excel]. Available from: http://www.unicef.org/infobycountry/ brazil_statistics.html.

8. Sena MCF, Silva EF, Pereira MG. Prevalência do aleitamento materno nas capitais brasileiras. Rev Assoc Med Bras 2007;53(6)520-4 Available from: www.scielo.br/scielo.php?script=sci_arttext\&pid=S0104 $42302007000600020 \& \operatorname{lng}=$ en.

[9]. Brazil Ministry of Health, Department of Health Care, Brasil, Department of Strategic and Programmatic Actions. II Survey on the prevalence of breastfeeding in the Brazilian capitals and the Federal District. Brasilia: Ministry of Health; 2009.

10. Rocha NB, Garbin AJI, Garbin CAS, Moimaz SAS. The act of breastfeeding: a qualitative study. Physis 2010;20(December (4))1293-305 Available from: www.scielo.br/scielo.php?script=sci_arttext\&pid=S0103$73312010000400012 \& \operatorname{lng}=$ en.

11. Meedya S, Fahy K, Parratt J, Yoxall J. Supporting women to achieve breastfeeding to six months postpartum-the theoretical foundations of a successful program. Women Birth 2015;28(4):265-71.

12. Scavenius M, Hulsel LV, Meijer J, Wendte H, Gurgel R. In practice, the theory is different: a processual analysis of breastfeeding in northeast Brazil. Soc Sci Med 2007;64(3):676-88.

13. Hinsliff-Smith RS, Spencer DW. Realities, difficulties, and outcomes for mothers choosing to breastfeed: primigravid mothers experiences in the early postpartum period (6-8 weeks). Midwifery 2014;30(1):e14-9.
14. Lutsiv O, Pullenayegum E, Foster G, Vera C, Giglia L, Chapman B, Fusch C, McDonald SD. Women's intentions to breastfeed: a population-based cohort study. BJOG 2013;120(12):1490-8.

15. Sipsma HL, Divney AA, Magriples U, Hansen N, Gordon D, Kershaw T Breastfeeding intentions among childbearing adolescents and young adults and their partners. Breastfeed Med 2013;8(4):374-80.

16. Ismail TAT, Muda WMW, Bakar MI. Intention of pregnant women to exclusively breastfeed their infants: the role of beliefs in the theory of planned behavior. Child Health Care 2013;18(2):123-32.

17. Linares AM, Rayens MK, Gomez ML, Gokun Y, Dignan MB. Intention to breastfeed as a predictor of initiation of exclusive breastfeeding in hispanic women.J Immigr Minor Health 2015;17(4):1192-810.1007/s10903-014-0049-0.

18. Issler H, de Sá MB, Senna DM. Knowledge of newborn healthcare among pregnant women; basis for promotional and educational programs on breastfeeding. Sao Paulo Med J 2001;119(1):7-9.

19. Machado AKF, Elert VW, Pretto ADB, Pastore CA. Intention to breastfeed and complementary feeding of postpartum women in a teaching hospital in southern Brazil. Cien Saude Colet 2014;19(7):1983-9.

20. Nogueira LT, Valsecki AJ, Martins CR, Rosell FL, Silva SRC. Delay in seeking dental treatment and perception of oral health in pregnant women. Odonto Clin Cient 2012;11(2):127-31.

21. Moimaz SAS, Rocha NB, Saliba O, Garbin CAS. The access of pregnants to dentistry treatment. Revista de Odontologia da Universidade Cidade de São Paulo 2007;19(1):39-45.

22. Moimaz SAS, Santos RR, Hidalgo LRC, Wakayama B, Rovida TAS. Impact of an educational and preventive program on practice of breastfeeding. Breastfeed Med 2013;8:228.

23. Center for Disease Control and Prevention. Program Epi Info version 7.0. Available from: http://www.cdc.gov/epiinfo/ Acessed 10.09.14.

24. Ayres M, Ayres Jr. MJr., Ayres DL, Santos AS. Program BioEstat version 5.0.3. Available from: http://www.mamiraua.org.br/download/index.php?dirpath $=$. /BioEstat\%205\%20Portugues\&order $=0$ Acessed 10.09.14.

25. Fishbein M, Ajzen I. Predicting and changing behaviour: the reasoned action approach. New York: Psychology Press; 2010.

26. Rea MF. The Brazilian national breastfeeding program: a success story. Int J Gynaecol Obstet 1990;31(1):79-82.

27. Piccinini CA, Lopes RS, Gomes AG, De Nardi T. Pregnancy and motherhood. Psicol Estud 2008;13(1)63-72 Available from: http://www.scielo.br/scielo. php?script=sci_arttext\&pid=S1413-73722008000100008\&lng=en\&nrm=iso.

28. Marques NM, Lira PI, Lima MC, da Silva NL, Filho MB, Huttly SR, Ashworth A Breastfeeding and early weaning practices in northeast Brazil: a longitudinal study. Pediatrics 2001;108(4):E66.

29. Boccolini CS, Carvalho ML, Oliveira MIC. Fatores associados ao aleitamento materno exclusivo nos primeiros seis meses de vida no Brasil: revisão sistemática. Rev Saúde Pública 2015;49:1-15.

30. Tsai SY. Impact of a breastfeeding-friendly workplace on an employed mother's intention to continue breastfeeding after returning to work. Breastfeed Med 2013;8:210-6.

31. Brazil Ministry of Health, Department of Health Care, Department of Strategic Programmatic Actions. Booklet for the working mother who breastfeed. Brasília: Ministry of Health; 2010 Available from: http://bvsms.saude.gov.br/bvs/ publicacoes/cartilha_mae_trabalhadora_amamenta.pdf.

32. Coutinho SB, Lira PI, de Carvalho Lima M, Ashworth A. Comparison of the effect of two systems for the promotion of exclusive breastfeeding. Lancet 2005;366 (9491):1094-100. 